\title{
STUDY OF CROWM TO RUMP LENGTH AND MEAN SAC DIAMETER: CO- RELATION TO PREGNANCY OUTCOME IN FIRST TRIMESTER"
}

Varsha Deshmukh¹, K.A.Yelikar², Kalpana Tibdwal'3.

1. Associate Professor, Department of Obstetrics \& Gynaecology, Government Medical College, Aurangabad.

2. Professor \& Head of the department (Unit Head), Department of Obstetrics \& Gynaecology, Government Medical College, Aurangabad.

3. Resident Chief, Department of Obstetrics \& Gynaecology, Government Medical College, Aurangabad.

\author{
CORRESPONDING AUTHOR \\ Dr. Varsha Deshmukh, \\ 120, Samarthnagar, \\ Aurangabad. \\ Email-deshmukhvl@yahoo.com
}

HOW TO CITE THIS ARTICLE:

Varsha Deshmukh, K. A. Yelikar, Kalpana Tibdwal. "Study of Crown to Rump length \& mean Sac Diameter: Corelation to Pregnancy outcome in first Trimester". Journal of Evolution of Medical and Dental Sciences 2013; Vol2, Issue 23, June 10; Page: 4244-4251.

ABSTRACT: OBJECTIVE: To find out whether the correlation of MSD and CRL with MA is related to normal and abnormal pregnancy outcome.METHOD: An observational, prospective study was conducted in department of OBGY; GMCH; Aurangabad. A total of 200 patients with single consecutive first trimester pregnancies at $5^{\text {th }}$ week of gestation underwent a TVS ultrasound to visualize the gestational sac (MSD) and Crown - Rump length (CRL). These parameters were correlated with menstrual age (MA). Pregnancies were weekly followed up till 12 weeks of gestation and outcome of pregnancy was studied. STATISTICAL ANALYSIS: 'Coefficient correlation (r) between the MSD with MA; and CRL with MA was established on the basis of pregnancy outcome. RESULTS: Out of 200 patients, 158 (79\%) had normal pregnancy outcome and 42 (21\%) had abnormal pregnancy outcome. The mean age in Group A was 25yrs ( \pm 4.4$)$ and in Group B was 23yrs $( \pm 4.1)$. The earliest age at which gestational sac was visualized was 4 weeks and 5 days. The average growth rate of MSD was $1.1 \mathrm{~mm}$ /day in Group A and $1.06 \mathrm{~mm} /$ day in Group B in first trimester. The earliest age at which CRL was visualized was 6weeks and 2 days. The average growth rate of CRL was $1.09 \mathrm{~mm} /$ day in Group A and $0.7 \mathrm{~mm} /$ day in Group B in first trimester. In normal pregnancy outcome, the Coefficient correlation ( $r$ ) between the MSD with MA was 1(at $p$ value of 0.01 levels). The Coefficient correlation ( $r$ ) between the CRL with MA in patients with normal pregnancy outcome was 1 (at $p$ value of 0.01 levels CONCLUSION: A positive correlation between MSD and CRL with MA is useful in predicting normal pregnancy outcome in first trimester.

KEYWORDS: CRL, MSD, MA, pregnancy outcome, TVS ultrasound.

INTRODUCTION: In modern obstetrics many women present in ANC OPD as soon as they miss their period. By means of ultrasound scanning we are able to measure different fetal anatomical landmarks and follow their evolution during gestation. Hence TVS ultrasound has become one of 
the most important tools for evaluation of fetus and represents a new approach in prenatal evaluation.( 1)Visualization of various parameters in early pregnancy like the MSD and CRL and their serial follow up on USG can help us in predicting the outcome of pregnancy.TVS ultrasound plays an important role in first trimester prenatal evaluation.

Various studies have been undertaken and correlation of MSD and CRL with MA for predicting pregnancy outcome has been studied. Hence the study was undertaken with the aim to:

1. To study the earliest age at which gestational sac and crown rump length was seen.

2. To establish the rate of increase of MSD and CRL per day.

3. To establish the correlation of MSD and CRL with MA in first trimester pregnancy outcome.

MATERIAL AND METHOD: An observational, prospective study was conducted in department of OBGY; GMCH; Aurangabad. The study had been approved by the Institutional Ethical Committee (IEC). Patients who came for antenatal check - up between the period September 2006 to August 2008 with the following inclusion and exclusion criteria were selected for study:

\section{INCLUSION CRITERIA:}

1) All patients at $5^{\text {th }}$ week of gestation who knew their exact dates of last menstrual period (LMP), and with no symptoms.

2) Patients at $5^{\text {th }}$ week of gestation who knew their exact dates of last menstrual period (LMP), and with following complaints -

$\rightarrow$ Pain in abdomen

$\rightarrow$ Bleeding per vaginum

$\rightarrow$ Spotting per vaginum

3) Patients up to age up to 40 years of age.

\section{EXCLUSION CRITERIA:}

1) Patients with extra - uterine pregnancy

2) Multiple gestation pregnancy

3) Patients with intra - uterine pregnancy with diagnosis of vesicular mole on follow up.

4) Patients conceived by artificial reproductive technique.

After a valid, informed and written consent of the patient was taken an ultrasonography was performed at each follow up by experienced consultants. Patients were examined on ultrasound machine using a convex transvaginal probe of $7.5 \mathrm{~Hz}$ frequency. The following parameters were evaluated:

a. Whether pregnancy was intra - uterine or extra - uterine.

b. If intrauterine, then location; size, number and regularity of gestational sac.

c. Appearance of crown - rump length and its measurement.

On the basis of pregnancy outcome; the cases were classified into two groups:

GROUP A - Comprised of patients with a normal pregnancy outcome i.e. if pregnancy continued to second trimester of pregnancy or if the patient had an uneventful first trimester of pregnancy. 
GROUP B - Comprised of patients with abnormal outcome i.e. who experienced first trimester embryonic or fetal death or demonstrable fetal anomaly. Also the patients with missed abortions, spontaneous abortions and blighted ovum were included in this group.

The statistical analysis was performed using the SPSS software package. Analysis was done using Coefficient correlation ( $\mathrm{r}$ ) between the various variables such as menstrual age v/s crown rump length and menstrual age $\mathrm{v} / \mathrm{s}$ mean sac diameter.

\section{OBSERVATIONS AND RESULTS}

TABLE I: Demographic distribution of Study Population

\begin{tabular}{|l|l|l|}
\hline & Group A & Group B \\
\hline Mean Maternal Age \pm S.D. (yrs) & $25 \pm 4.4$ & $23 \pm 4.1$ \\
\hline Primigravida & 40 & 14 \\
\hline Multigravida & 118 & 28 \\
\hline
\end{tabular}

The mean age in Group A and Group B were 25yrs $( \pm 4.4)$ and 23yrs $( \pm 4.1)$. The no. of Primigravida cases in Group A were 40 and in Group B were 14. Similarly, the no. of multigravida cases in Group A were 118 and in Group B were 28.

TABLE II: Presence of symptoms in study subjects during follow - up:

\begin{tabular}{|l|l|l|}
\hline Symptoms & No. of Patients & Percentage \\
\hline Spotting per vaginum & 19 & 42.22 \\
\hline Pain in abdomen & 12 & 26.66 \\
\hline Pain in abdomen + Spotting per vaginum & 09 & 20.00 \\
\hline Pain in abdomen + Bleeding per vaginum & 03 & 06.66 \\
\hline Bleeding per vaginum & 02 & 04.44 \\
\hline Total & $\mathbf{4 5}$ & $\mathbf{1 0 0}$ \\
\hline
\end{tabular}

As can be seen above $22.5 \%$ had symptoms as listed. 19 patients $(42.22 \%)$ had spotting per vaginum as chief complaints, 12 patients $(26.66 \%)$ had pain in abdomen. Followed in order was the combination of both complaints i.e. pain and spotting per vaginum in 9 patients (20\%); whereas only in 2 patients (4.44\%), the least common complaint was bleeding per vaginum. $77.5 \%$ of patients did not develop any symptoms during follow up 


\section{ORIGINAL ARTICLE}

TABLE III: Outcome of pregnancy in the patients studied.

\begin{tabular}{|l|l|l|}
\hline \multicolumn{2}{|l|}{ Pregnancy Outcome } & \multirow{2}{*}{ Total } \\
\cline { 1 - 2 } Normal & Abnormal & \\
\hline 158 & 20 & $178(89)^{*}$ \\
\hline 0 & 22 & $22(11)$ \\
\hline $\mathbf{1 5 8}$ & $\mathbf{4 2}$ & $\mathbf{2 0 0 ( 1 0 0 \% )}$ \\
\hline
\end{tabular}

*Figures in parenthesis are percentages.

Out of the total number of patients studied ( $\mathrm{n}=200)$; in 178 patients (89\%) yolk sac was visualized; out of which 158 patients had normal pregnancy outcome and 20 had an abnormal pregnancy outcome. In the remaining 22 patients (11\%) yolk sac was not visualized and they had an abnormal pregnancy outcome.

TABLE IV: Comparison of Mean Sac Diameter with Menstrual Age in the study groups:

\begin{tabular}{|c|c|c|c|c|c|c|}
\hline \multirow{3}{*}{ Gestational age (wks) } & \multicolumn{6}{|c|}{ Mean Sac Diameter } \\
\hline & \multicolumn{3}{|c|}{ Group A } & \multicolumn{3}{|c|}{ Group B } \\
\hline & \multicolumn{3}{|c|}{$\operatorname{MSD}(\mathrm{mm}) \pm$ S.D. } & \multicolumn{2}{|c|}{$\operatorname{MSD}(\mathrm{mm}) \pm$} & S.D. \\
\hline $5^{\text {th }}$ & 05.0 & \pm & 0.294 & 04.997 & \pm & 00.201 \\
\hline $6^{\text {th }}$ & 12.6 & \pm & 0.871 & 11.180 & \pm & 01.661 \\
\hline $7^{\text {th }}$ & 19.8 & \pm & 1.099 & 17.288 & \pm & 03.910 \\
\hline $8^{\text {th }}$ & 28.5 & \pm & 1.368 & 24.433 & \pm & 05.383 \\
\hline $9^{\text {th }}$ & 37.1 & \pm & 1.362 & 34.871 & \pm & 00.940 \\
\hline $10^{\text {th }}$ & 45.6 & \pm & 1.734 & 42.250 & \pm & 00.450 \\
\hline $11^{\text {th }}$ & 53.3 & \pm & 1.652 & $\mathrm{Nil}^{*}$ & & \\
\hline $12^{\text {th }}$ & 62.0 & \pm & 1.712 & Nil * & & \\
\hline
\end{tabular}

* Pregnancy was terminated for being an abnormal pregnancy.

The mean sac diameter (MSD) in Group A patients was $5 \mathrm{~mm}$ at initial examination at $5^{\text {th }}$ week of gestation. The earliest menstrual age at which the gestational sac was visualized was 4 week 5 day. The size of MSD increased gradually at $1.11 \mathrm{~mm} /$ day corresponding to the gestational age. Correlation coefficient (r) of MSD with MA was 1 at a $\mathrm{p}$ value of 0.01 levels. MA has a positive correlation for MSD (as shown below in graph - 1) 
In Group B patients; the mean sac diameter (MSD) was $4 \mathrm{~mm}$ at initial examination at $5^{\text {th }}$ week of gestation. The earliest menstrual age at which the gestational sac was visualized was 5 week 1 day. It increased gradually in size at $1.06 \mathrm{~mm} /$ day till $10^{\text {th }}$ week of gestation; and after $10^{\text {th }}$ week MSD could not be visualized as pregnancy was terminated for being an abnormal pregnancy.

\section{GRAPH - 1: Correlation of Mean Sac Diameter with Menstrual Age:}

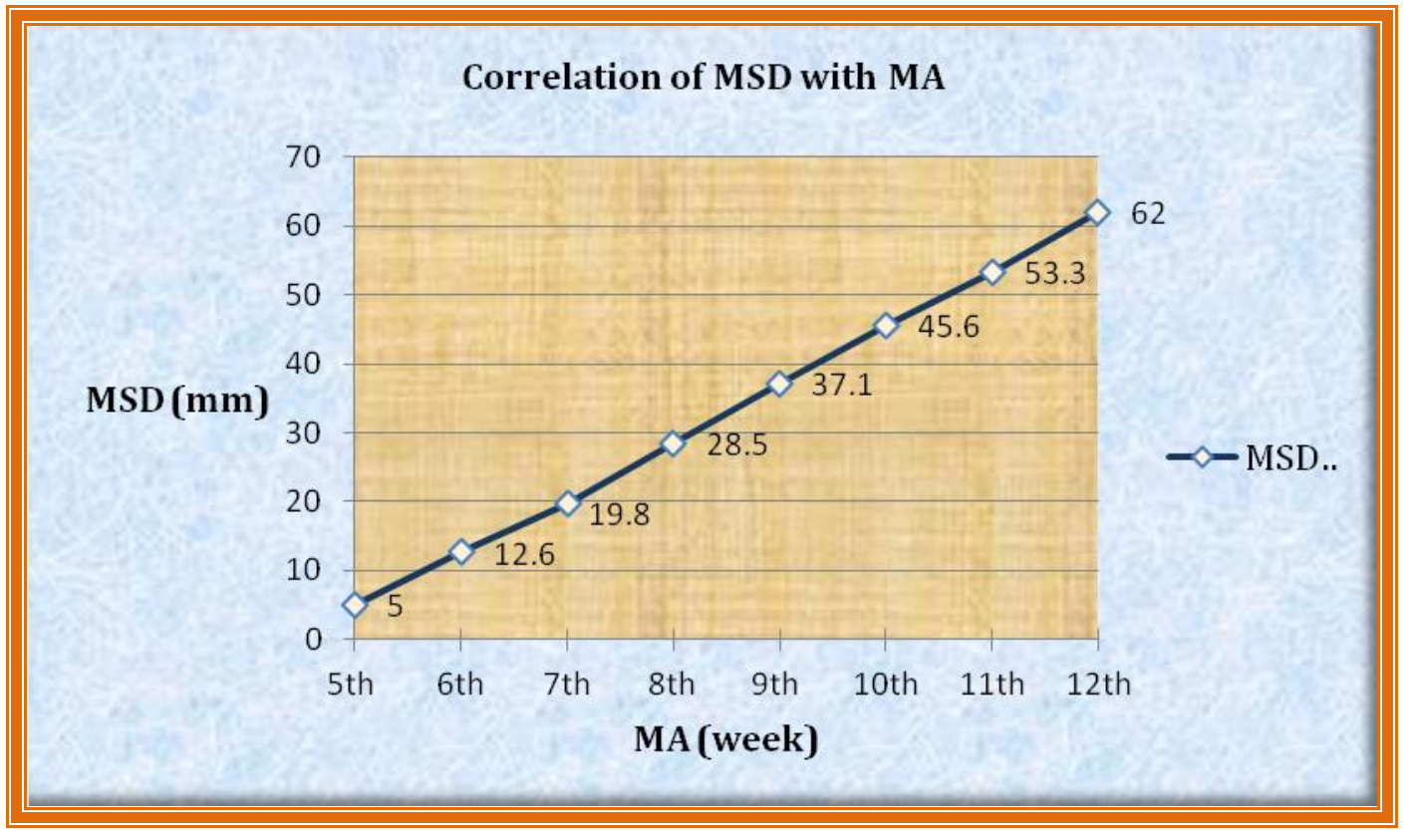

TABLE V: Comparison of Crown Rump Length with menstrual age in two study groups:

\begin{tabular}{|c|c|c|c|c|c|}
\hline \multirow{3}{*}{ Gestational age (wks) } & \multicolumn{5}{|c|}{ Crown Rump Length } \\
\hline & \multicolumn{2}{|c|}{ Normal Outcome } & \multicolumn{3}{|c|}{ Abnormal Outcome } \\
\hline & CRL(mm) & \pm S.D. & CRL(mm) & \pm & S.D. \\
\hline $5^{\text {th }}$ & Nil & & Nil & & \\
\hline $6^{\text {th }}$ & 04.95 & $\pm \quad 0.319$ & 04.56 & \pm & 0.485 \\
\hline $7^{\text {th }}$ & 11.68 & $\pm \quad 0.943$ & 09.56 & \pm & 1.343 \\
\hline $8^{\text {th }}$ & 18.03 & \pm 2.102 & 15.50 & \pm & 0.649 \\
\hline $9^{\text {th }}$ & 25.36 & $\pm \quad 2.366$ & 19.94 & \pm & 0.954 \\
\hline $10^{\text {th }}$ & 32.46 & $\pm \quad 1.227$ & 23.85 & \pm & 0.850 \\
\hline $11^{\text {th }}$ & 41.24 & \pm 1.649 & $\mathrm{Nil} *$ & & \\
\hline $12^{\text {th }}$ & 50.83 & $\pm \quad 2.542$ & Nil * & & \\
\hline
\end{tabular}

*Pregnancy was terminated for being an abnormal pregnancy.

In normal pregnancy outcome patients, at $5^{\text {th }}$ week the CRL was not visualized. But on follow up; embryo was visualized by $6^{\text {th }}$ week of gestation and increased gradually at $1.09 \mathrm{~mm} /$ day with increase in gestational age. 
The earliest gestational age at which CRL appeared was at 6 weeks 2 days.

Correlation coefficient ( $\mathrm{r}$ ) of CRL with MA was 1.000 at a p value of 0.01 levels.

$>$ MA has a positive correlation for CRL (as shown in graph - 2)

In patients with abnormal pregnancy outcome; the embryo was not visualized at $5^{\text {th }}$ week of gestation but later on it was visualized at $6^{\text {th }}$ week. The earliest gestational age at which the embryo was visualized was 6 week 0 day. It was seen only up to $10^{\text {th }}$ week of gestation as pregnancy was terminated for being an abnormal pregnancy.

GRAPH - 2: Correlation of Crown Rump Length with menstrual age:

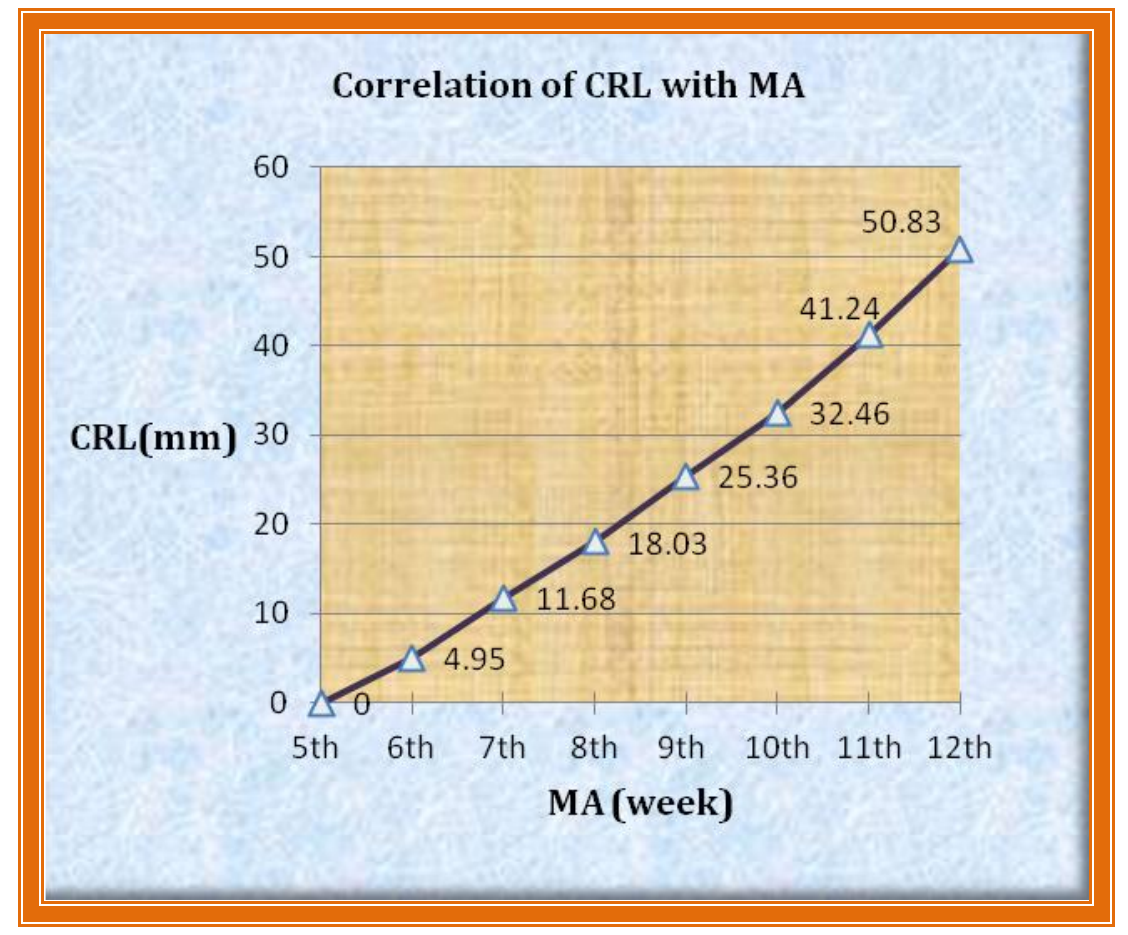

DISCUSSION: The present study was an observational and prospective study during the period of September 2006 to August 2008.In the present study, a consecutive selection of 263 patients was done; attending the ANC clinic for routine checkup. These patients knew their exact dates of last normal menstrual period (LNMP). Out of the 263 patients selected; only 200 patients were studied extensively with a weekly USG follow up; and the remaining 63 patients were lost to follow up.

Table I shows the demographic distribution of the study population. Out of the total no. of patients studied, the mean age of Group A was 25yrs and Group B was 23yrs. Out of the total patients in Group A (n=158), Primigravida were 40 in number and Multigravida were 118. Out of the total patients in Group B (n=42), Primigravida were 14 in number and Multigravida were 28.

Table II shows the distribution of the patients with various symptoms during follow up. Out of the total number of patients studied $(n=200), 45$ patients $(22.5 \%)$ had developed symptoms. Out of the 45 patients, 19 patients (42.22\%) had spotting PV as the commonest symptom, followed by pain in abdomen in 12 patients (26.66\%). A combination of both these symptoms was present as chief complain in 9 patients (20\%). Bleeding PV alone and in combination with pain was the least 
common complaint in 5 patients (11.11\%). Remaining 155 patients (77.5\%) did not develop any symptoms during follow up.

Table III showed the outcome of pregnancy of the patients studied. In the present study out of the total number of patients studied $(n=200)$; 158 patients belonged to group A and 42 patients belonged to group B.

Table IV shows the comparison of MSD diameter with menstrual age in both, Group A and Group B. In the present study the earliest gestational age at which the mean sac diameter was visualized was 4 week and 5days. This is in agreement with Robert et al ${ }^{2}(1996)$, which suggested that gestation sac appears at 4 weeks of LMP. Swedan et al ${ }^{3}(2006)$ observed that intra - uterine gestational sac often can be identified by 31 days on TVS and can consistently be identified by 35 days gestational age (GA). In the present study the MSD progressively increased by $1.11 \mathrm{~mm} /$ day in group A and $1.06 \mathrm{~mm} /$ day in group B. This is in agreement with Nyberg et al ${ }^{4}$ (1986) and Robert et al ${ }^{2}$ (1996) according to which gestational sac grows at a rate of $1 \mathrm{~mm} /$ day and $1-2 \mathrm{~mm} /$ day respectively in patients with normal pregnancy outcome. Graph - 1 depicts the correlation between the MSD and the MA. However according to Swedan et al ${ }^{32006}$ ), mean sac growth rate was found to be $1.13 \mathrm{~mm} /$ day in normal gestation as compared to $0.7 \mathrm{~mm} /$ day in abnormal intra - uterine gestation. This was because they used an ultrasound probe of higher frequency. In the present study, coefficient correlation between MSD and MA in Group A was $r=1.000$ at $p$ value of 0.01 . MA had a positive correlation for MSD i.e. as the menstrual age increase, the mean sac diameter also increases. This is in agreement with Nyberg et al ${ }^{4}$ (1986), Swedan et al ${ }^{3}(2006)$ and Robert et al ${ }^{2}(1996)$.

Table $\mathrm{V}$ depicts the comparison of the CRL with the MA in both the groups. In the present study, in Group A the embryo was visualized earliest at 6 weeks 2days and its mean size at the appearance is $4.9 \mathrm{~mm}$ with an SD of $0.319 \mathrm{~mm}$. However in Group B (Table IX) patients; though CRL was visualized at $6^{\text {th }}$ week of gestation. It was not visualized after $11^{\text {th }}$ week of gestation as pregnancy got terminated This is in agreement with Pratap Kumar et al ${ }^{6}$ (1995) and Robert et al 2 (1996), study in which fetal pole could be identified from 6 weeks onwards when MSD measured $16 \mathrm{~mm}$ or 3 - 7 days after the yolk sac.

In the present study, in Group A patients the CRL increased by $1.09 \mathrm{~mm} /$ day as against in Group B in which the CRL increased by less than $0.7 \mathrm{~mm} /$ day. This is in agreement with Pratap Kumar et al ${ }^{5}$ (1995) and Robert et al ${ }^{2}$ (1996), study in which CRL increases at 1mm/day. Graph - 2 depicts the correlation between the CRL and the MA.

In the present study, correlation coefficient (r) of CRL with MA was 1.000 at a $p$ value of 0.01 levels. CRL has a positive correlation for MA i.e. as the menstrual age increase, the CRL also increases. This is in agreement with Pratap Kumar et al ${ }^{6}$ (1995) and levi et al ${ }^{7}$ (1996).

As the author we would say there are a few limitations to this study.

First, the age of the patient is not taken into consideration for miscarriages. Age is a very important factor in miscarriages as the less healthy embryos are formed due to aging process. this is in agreement to $\mathrm{S}$ Choong et al(2011) ${ }^{8}$

Second, there may be variability in the intra - inter observer reproducibility of the measurements of the sacs and CRL. Although small, this may be of clinical significance. A Pexters, J Cuts et al(2011) 9 
Third, the slow growing sacs are not always "sick sacs". Great care should be taken before making a diagnosis of miscarriage. Y Abdullah, A Daemen et al (2011). A theoretical error is possible, although it was always kept in mind

Fourth, the miscarriages caused after 12 weeks to 14 weeks are not taken into consideration as per the study protocol . Although the possibility is low , 0.5\%,only, Y Abdullah, A Daemen et al (2011),this small miscarriages can be missed

CONCLUSION: The present study concludes that the correlation of the crown rump length and menstrual age is positive i.e. as menstrual age increases, the CRL also increases. The pregnancy outcome is good in these cases .A positive correlation also exist between the MSD (Mean Sac Diameter)and menstrual age i.e as menstrual age increases the MSD also increases, pregnancy outcome is good in these cases Hence the linear growth of CRL and MSD can be used as a predictor of first trimester pregnancy outcome

\section{BIBLIOGRAPHY:}

1. Kucuk T, Duru N K, Yenen M C, et al: Yolk Sac Size and Shape as Predictors of Poor Pregnancy: Journal of Perinatal Medicine August 1999: Vol. - 27 (4): Pg $316-20$.

2. Robert S H: Early Pregnancy: Normal and Abnormal: Clinical Obstetrics and Gynaecology 1996: Vol - 39 (1): Lippincott - Raven Publishers Pg 188 - 98.

3. Sweedan K: Sonographic Evidence of Early Pregnancy Failure: Ain Sham's Journal of Obstetrics and Gynaecology, February 2006: Vol - 3:04 - 08.

4. Nyberg D A, Faye C L, Filly R A et al: Threatened Abortion: Sonographic Distinction of Normal and Abnormal Gestation Sacs: Radiology February 1986: Vol - 158: Pg 397 - 00.

5. Callen $\mathrm{P}$ W: Ultrasound Evaluation During the First Trimester of Pregnancy: Ultrasonography in Obstetrics and Gynecology: Callen P W: Ed - $5^{\text {th }}$, by Saunders Elsevier Publications: Pg 181 - 4, 189 - 91, 193 - 96, 200 - 09

6. Pratap Kumar, Sridevi V, et al: Transvaginal Sonographic Predictive Parameters in Early Pregnancy Loss: Journal of Obstetrics and Gynecology of India 1995: Vol - 45: dated 17.1.1995: Pg 14 - 8.

7. Levi C S, Lyons E A, Lindsay D J, et al: Early Diagnosis of Nonviable Pregnancy with Endovaginal US: Radiology May 1988: Vol - 167: $\quad$ Pg 383 - 85.

8. S Choong, L Rambaunts, A Ugoni et al: USG Prediction of spontaneous mis carriages in embryos "USG Obstet Gynecol, 2003"22:571-577

9. A Pexters J Cuts D Van Schbroeck et al: clinical implication of intra- inter observer reproducibility of TVS USG measurement of gestational sac and CRL in 6-9 weeks of gestation: USG Obstet Gynecol,2011"38:510-515

10. Y Abdullah, A Daemen,S Guha et al: gestational sac and embryonic growth are not useful as criteria to define miscarriages: a multicentric study USG Obstet Gynecol,2011"38:503-509

11. Y Abdullah, A Daemen Ekirk et al :limitation of current definition of miscarriage using MSD and CRL measurements: a multicentric study: USG Obstet Gynecol,2011"38:497 -502 